\title{
Phát triển kinh tế tư nhân: Từ nhận thức đến hành động
}

\author{
ThS. Lê Minh Hương \\ Viện Chiến lược và Chính sách tài chính
}

$09 / 11 / 2017$ 15:51:11

https://nif.mof.gov.vn/webcenter/portal/mvclcstc/r/chitiettimkiem?dDocName=MOFUCM116788 \&dID $=60442 \&$ afrLoop $=71550289104363 \# \% 40 \% 3 F$ _afrLoop $\% 3 D 71550289104363 \% 26$ center Width\%3D100\%2525\%26dDocName\%3DMOFUCM1 16788\%26dID\%3D60442\%26leftWidth\%3 D0\%2525\%26rightWidth\%3D0\%2525\%26showFooter\%3Dfalse\%26showHeader\%3Dfalse \%26 _adf.ctrl-state\%3D140qqwwhpg_4 


\title{
CỔNG THÔNG TIN ĐIỆN TỬ Bộ TÀI CHÍNH
}

\author{
ThS. Lê Minh Hương
}

Viện Chiến lược và Chính sách tài chính

Nhận thức của Đảng về vai trò của kinh tế tư nhân 1 (KTTN) đã có những chuyển biến tích cực, từng bước thừa nhận sự tồn tại khách quan của KTTN và khẳng định vai trò "động lực" và "động lực quan trọng" của KTTN trong nền kinh tế thị trường (KTTT) định hướng XHCN. Để KTTN đảm nhận đúng vai trò, phát huy được nội lực và tiềm năng sẵn có, Nghị quyết số $10-N Q / T W$ ngày $03 / 6 / 2017$ của Ban Chấp hành Trung ương Đảng khóa XII đã xác định cần "xóa mọi định kiến, rào cản để KTTN phát triển".

\section{Quá trình thay đổi nhận thức của Đảng về kinh tế tư nhân}

Trước năm 1986: Tồn tại nhưng chưa được thừa nhận

Sự tồn tại của KTTN trong giai đoạn này được thể hiện qua Nghị quyết của Bộ Chính trị tháng 9/1954: "Công thương nghiệp tư nhân nhât luật được bảo hộ... Phải làm cho các xí nghiệp công và tư hiện có được tiếp tục kinh doanh". Trước tình hình khủng hoảng kinh tế - xã hội, đời sống nhân dân rất khó khăn, Hội nghị Trung ương Đảng lần thứ 6 (Khoá IV) tháng 9/1979 chủ trương cho sản xuất "bung ra" và sử dụng đúng mức các thành phần kinh tế. Đại hội lần thứ $\mathrm{V}$ của Đảng tháng 3/1982 tiếp tục khẳng định chủ trương trên. Chủ trương xuyên suốt của Đảng trong giai đoạn này là xây dựng một nền kinh tế quá độ đi lên chủ nghĩa xã hội (CNXH) với cơ cấu kinh tế 2 thành phần là kinh tế XHCN (gồm kinh tế quốc doanh và tập thể), quản lý theo cơ chế kế hoạch hóa tập trung và kinh tế phi XHCN (chủ yếu là kinh tế cá thể và tiểu chủ), nằm trong diện cải tạo và xóa bỏ với mong muốn nhanh có một nền kinh tế XHCN.

Giai đoạn 1986 - 1996: Được công khai thừa nhận

Đại hội Đảng VI (1986) đã nhìn nhận và đánh giá lại thực tế phát triển kinh tế - xã hội của đất nước, phê phán bệnh "chủ quan, duy ý chí, đơn giản hoá", "chưa thật sự thừa nhận những quy luật của sản xuất hàng hoá đang tồn tại khách quan" dẫn đến khủng hoảng kinh tế - xã hội, đồng thời có những gợi mở về đường lối trong phát triển kinh tế đất nước. Từ những gợi mở này, Nghị quyết Hội nghị lần thứ 6 của Ban Chấp hành Trung ương VI (1989) lần đầu tiên đưa ra khái niệm KTTN và khẳng định: "Trong điều kiện của nước ta, các hình thức KTTN (cá thể, tiều chủ, tư bản tư nhân) vần cần thiết lâu dài cho nền kinh tế và nằm trong cơ cấu của nền kinh tế hàng hóa đi lên CNXH". Tiếp đó, Nghị quyết số 16 của Bộ Chính trị khóa VI (1988) và Nghị quyết Hội nghị Trung ương 6 khóa VI tiếp tục khẳng định đường lối đổi mới, nhất quán thực hiện chính sách kinh tế nhiều thành phần, khẳng định KTTN được phát triển không hạn chế địa bàn, quy mô, trong các ngành nghề mà pháp luật không cấm. Đây 
là nền tảng để Nhà nước ban hành Luật Công ty và Luật Doanh nghiệp tư nhân (1990), tạo cơ sở pháp lý đầu tiên cho việc hình thành và phát triển các doanh nghiệp tư nhân với các loại hình công ty trách nhiệm hữu hạn, công ty cổ phần và doanh nghiệp tư nhân.

Đại hội VII đã có những nhìn nhận rõ nét hơn về vị trí và vai trò của KTTN: "KTTN được phát triển, đặc biệt trong lĩnh vực sản xuất, theo sự quản lý, hướng dẫn của Nhà nước, trong đó, kinh tế cá thể và tiểu thủ có phạm vi hoạt động tương đối rộng ở những nơi chưa có điều kiện tổ chức kinh tế tập thể, hướng kinh tế tư bản tư nhân phát triển theo con đường tư bản nhà nước dưới nhiều hình thức". "Kinh tế tư bản tư nhân được phát triển không hạn chế về quy mô và địa bàn hoạt động trong những ngành, nghề mà luật pháp không cấm. Nhà nước có thể liên doanh bằng nhiều hình thức với tư nhân trong và ngoài nước, hình thành loại doanh nghiệp thuộc thành phần tư bản nhà nước".

Từ chỗ coi kinh tế tư bản tư nhân là một thành phần kinh tế "tàn dư" của chế độ xã hội cũ, có thể sử dụng nhưng cần "cải tạo" bằng những bước đi thích hợp, Đại hội VII đã thực sự coi KTTN (gồm kinh tế cá thể và kinh tế tư bản tư nhân) là một thành phần kinh tế độc lập, có tiềm năng phát triển và đóng góp cho sự phát triển kinh tế đất nước. Chính vì vậy, Hội nghị Trung ương 2 khóa VII đã đưa ra chủ trương: "Bổ sung và sửa đổi thể chế nhẳm bảo đảm cho tập thể, cá thể và tư nhân được phát triển không hạn chế về quy mô và địa bàn hoạt động trong những lĩnh vực mà pháp luật không câm; được tự lựa chọn hình thức kinh doanh, kể cả liên doanh với nước ngoài theo những điều kiện do luật định".

Giai đoạn1996 - 2001: Có vị trí quan trọng lâu dài trong nền kinh tế thị trường định hướng XHCN

Đại hội Đảng lần thứ VIII (1996) tiếp tục kế thừa những quan điểm của các đại hội trước về phát triến kinh tế nhiều thành phần, công nhận thêm thành phần tiểu chủ với điểm nhấn là: "Kinh tế cá thể, tiểu chủ có vị trí quan trọng, lâu dài”; đồng thời khẳng định cần phải đối xử công bằng giữa các thành phần kinh tế, "tạo điều kiện kinh tế và pháp lý thuận lợi để các nhà kinh doanh tư nhân yên tâm đầu tư làm ăn lâu dài".

Đến Đại hội IX (tháng 01/2001), Đảng ta khẳng định kinh tế tư bản tư nhân là thành phần kinh tế có vị trí quan trọng lâu dài trong nền KTTT định hướng XHCN, "kinh tế tư bản tư nhân được khuyến khích phát triển không hạn chế về quy mô trong những ngành, nghề, lĩnh vực và địa bàn mà pháp luật không cấm". Đây là bước phát triển mới trong tư duy của Đảng về vị trí, vai trò của KTTN trong phát triển kinh tế. Nhờ vậy từ quan điểm "Tư bản tư nhân được kinh doanh trong những ngành có lợi cho quốc kế dân sinh do luật pháp quy định" (Đại hội VII), Đảng đã khẳng định "Tạo môi trường kinh doanh thuận lợi về chính sách, pháp lý để kinh tế tư bản tư nhân phát triển trên những hướng ưu tiên của Nhà nước, kể cả đầu tư ra nước ngoài; chuyển thành doanh nghiệp cổ phần, bán cổ phần cho người lao động; liên doanh liên kết với nhau, với kinh tế tập thể và kinh tế nhà nước" (Đại hội IX). KTTN trong Nghi quyết Đại hội IX bao gồm các thành phần: kinh tế tư bản tư nhân; kinh tế cá thể, tiểu chủ; kinh tế có vốn đầu tư nước ngoài.

Giai đoạn 2002 - 2015: Là một trong những động lực của nền kinh tế 
Trên cơ sở đánh giá những đóng góp của KTTN trong phát triển kinh tế, huy động các nguồn lực xã hội vào sản xuất - kinh doanh, tạo thêm việc làm, cải thiện đời sống nhân dân, tăng ngân sách nhà nước, góp phần giữ vững ổn định chính trị - xã hội của đất nước; đồng thời cụ thể hóa quan điểm của Đại hội IX, Hội nghị lần thứ năm Ban Chấp hành Trung ương khóa IX (nắm 2002) đã thông qua Nghị quyết số 14-NQ/TW về tiếp tục đổi mới cơ chế, chính sách, khuyến khích, tạo điều kiện phát triển KTTN. Đây là lần đầu tiên kể từ khi đổi mới, Hội nghi Ban Châ p hành Trung ương có một nghị quyết chuyên đề về KTTN, mở ra những đường hướng rõ nét hơn về việc xây dựng cơ chế, chính sách khuyến khích KTTN phát triển. Nghị quyết khẳng định "KTTN là bộ phận cấu thành quan trọng của nền kinh tế quốc dân. Phát triển KTTN là vấn đề chiến lược lâu dài trong phát triển nền kinh tế nhiều thành phần định hướng XHCN, góp phần quan trọng thực hiện thắng lợi nhiệm vụ trung tâm là phát triển kinh tế, công nghiệp hóa, hiện đại hóa, nâng cao nội lực của đât nước trong hội nhập kinh tế quốc tế”. Chính vì vậy cần sửa đổi, bổ sung một số cơ chế, chính sách (chính sách đất đai, tài chính, tín dụng, lao động - tiền lương, hỗ trợ về đào tạo, khoa học và công nghệ...) nhằm tạo môi trường thuận lợi về thể chế và tâm lý xã hội cho KTTN phát triển rộng rãi trong những ngành, nghề sản xuất - kinh doanh mà pháp luật không cấm, không hạn chế về quy mô, nhất là trên những định hướng ưu tiên của Nhà nước.

Những bước tiến mới trong tư duy của Đảng về vị trí, vai trò của KTTN đã thể hiện rõ qua việc khẳng định: "KTTN có vai trò quan trọng, là một trong những động lực của nền kinh tế", đồng thời xác định: "Hoàn thiện cơ chế, chính sách để phát triển mạnh kinh tế tư nhân trở thành một trong những động lực của nền kinh tế”.

Năm 2016 đến nay: Là một động lực quan trọng của nền kinh tế

Đại hội XII (2016), Đảng đã khẳng định: "Nền KTTT định hướng XHCN ở Việt Nam có nhiều hình thức sở hữu, nhiều thành phần kinh tế, trong đó kinh tế nhà nước giữ vai trò chủ đạo, KTTN là một động lực quan trọng của nền kinh tế; các chủ thể thuộc các thành phần kinh tế bình đẳng, hợp tác và cạnh tranh theo pháp luật". Không chỉ xác nhận "KTTN là một động lực quan trọng” trong công cuộc phát triển đất nước, Đảng ta khẳng định chủ trương: "Khuyến khích hình thành các tập đoàn kinh tế tư nhân đa sở hữu và tư nhân góp vốn vào các tập đoàn kinh tế nhà nước". Trên cơ sở những tư tưởng nền tảng trong Nghị quyết Đại hội Đảng XII cùng với việc đánh giá 15 năm thực hiện Nghị quyết chuyên đề đầu tiên về KTTN Nghị quyết 14, Hội nghị lần thứ 5 Ban chấp hành Trung ương Đảng khóa XII đã ban hành Nghị quyết số 10-NQ/TW ngày 03/6/2017 về phát triển KTTN trở thành một động lực quan trọng của nền KTTT định hướng XHCN với kỳ vọng sẽ tạo đà cho KTTN bứt phá, thực hiện được vai trò "động lực quan trọng" trong phát triển kinh tế.

Qua các kỳ đại hội, quan điểm của Đảng ta về KTTN, phát triển KTTN đã có những bước chuyển quan trọng. Việc KTTN từ chỗ được thừa nhận công khai, tạo điều kiện phát triển đến được xác định là “động lực quan trọng” đã khẳng định sự tồn tại khách quan, tất yếu của KTTN trong thời kỳ quá độ lên CNXH ở nước ta.

2. Để kinh tế tư nhân trở thành động lực quan trọng của nền kinh tế 
Những chuyển biến trong tư duy của Đảng đã góp phần tích cực thúc đẩy KTTN không ngừng phát triển về số lượng và đóng góp ngày càng nhiều trong sự nghiệp đổi mới và phát triển đất nước. Đền hết năm 2016, cả nước có 4,6 triệu hộ kinh doanh phi nông nghiệp và 495.826 doanh nghiệp thuộc KTTN, đóng góp khoảng 39 - 40\% GDP; tỷ lệ đóng góp vào NSNN trung bình khoảng 29\% trong giai đoạn 2005 - 2016; tỷ trọng đầu tư của KTTN trong tổng đầu tư toàn xã hội tăng từ bình quân 33,6\% trong giai đoạn 2001 - 2010 lên bình quân 38,46\% trong giai đoạn 2011 2016... Tuy nhiên, đánh giá thực trạng phát triển của KTTN trong 15 năm qua, Đảng ta chỉ rõ: "KTTN chưa đáp ứng được vai trò là một động lực quan trọng của nền kinh tế" 2 . Chính vì vậy, Hội nghị lần thứ 5 Ban Chấp hành Trung ương Đảng khóa XII nhấn mạnh: "Xóa bỏ mọi định kiến, rào cản; cải cách mạnh các thủ tục hành chính rườm rà, tạo điều kiện thuận lợi cho KTTN phát triển", theo đó đã xác định 6 quan điểm lớn:

(1) Phát triển KTTN lành mạnh theo cơ chế thị trường là một phương sách quan trọng để giải phóng sức sản xuất; huy động, phân bố và sử dụng có hiệu quả các nguồn lực phát triển.

(2) Khuyến khích, tạo điều kiện thuận lợi để KTTN phát triển nhanh, bền vững, đa dạng với tốc độ tăng trưởng cao cả về số lượng, quy mô, chất lượng và tỷ trọng đóng góp trong GDP, thúc đẩy KTTN trở thành một trong những nòng cốt để phát triển.

(3) Xoá bỏ mọi rào cản, định kiến, tạo mọi điều kiện thuận lợi để phát triển KTTN lành mạnh và đúng định hướng; phòng, chống mọi biểu hiện của "chủ nghĩa tư bản thân hữu", quan hệ "lợi ích nhóm", thao túng chính sách, cạnh tranh không lành mạnh để trục lợi bất chính.

(4) KTTN được phát triển ở tất cả các ngành, lĩnh vực mà pháp luật không câm; khuyến khích hình thành các tập đoàn KTTN đa sở hữu và tư nhân góp vốn vào các tập đoàn kinh tế nhà nước, có đủ khả năng tham gia mạng sản xuất và chuỗi giá trị khu vực, toàn cầu.

(5) Khuyến khích KTTN tham gia góp vốn, mua cổ phần của các doanh nghiệp nhà nước khi cổ phần hóa hoặc Nhà nước thoái vốn; thúc đẩy phát triển mọi hình thức liên kết sản xuất - kinh doanh.

(6) Xây dựng đội ngũ doanh nhân Việt Nam ngày càng vững mạnh, có ý thức chấp hành pháp luật, trách nhiệm với xã hội và kỹ năng lãnh đạo, quản trị cao; chú trọng xây dựng văn hóa doanh nghiệp, đạo đức doanh nhân.

Bên cạnh việc xác định 6 quan điểm chỉ đạo lớn, Nghị quyết số 10$\mathrm{NQ} / \mathrm{TW}$ đề ra các mục tiêu cụ thể trong phát triển KTTN: Phấn đấu đến năm 2020 có ít nhất 1 triệu doanh nghiệp; đến năm 2025 có hơn 1,5 triệu doanh nghiệp và đến năm 2030, có ít nhất 2 triệu doanh nghiệp. Tốc độ tăng trưởng của KTTN cao hơn tốc độ tăng trưởng chung của nền kinh tế. Phấn đấu tăng tỉ trọng đóng góp của khu vực KTTN vào GDP để đến năm 2020 đạt khoảng $50 \%$, năm 2025 khoảng $55 \%$, đến năm 2030 khoảng 60 - 65\%. Bình quân giai đoạn 2016 - 2025, năng suất lao động tăng khoảng 4 - $5 \% /$ năm; thu hẹp khoảng cách về trình độ công nghệ, chất lượng nhân lực và năng lực cạnh tranh của doanh nghiệp tư nhân so với nhóm dẫn đầu ASEAN - 4; nhiều doanh nghiệp tư nhân tham gia mạng sản xuất, 
chuỗi giá trị khu vực và toàn cầu.

Trên nền tảng của 6 quan điểm và các mục tiêu cụ thể, Nghị quyết số 10$\mathrm{NQ} / \mathrm{TW}$ đã đề ra 5 nhóm giải pháp chủ yếu trong đó nhóm giải pháp thứ nhất và thứ năm tập trung vào giải quyết về mặt nhận thức, tư tưởng và hành động trong triển khai các cơ chế, chính sách về phát triển KTTN; tăng cường sự lãnh đạo của Đảng và các tổ chức đối với KTTN. Ba nhóm giải pháp nhằm hướng tới xoá bỏ mọi rào cản, tạo mọi điều kiện thuận lợi để phát triển KTTN lành mạnh và đúng định hướng.

Quan điểm của Đảng đã có sự chuyển biến mang tính đột phá với việc thông qua Nghị quyết chuyên đề lần thứ hai về phát triển KTTN với tư tưởng coi KTTN, trong đó coi KTTN là một động lực quan trọng phát triển kinh tế. Đế tránh tạo khoảng cách giữa chính sách và thực thi, đảm bảo cho KTTN phát triển như kỳ vọng, Đảng đã thống nhất được nhận thức về phát triển KTTN, đồng thời đề ra được những nhóm giải pháp cụ thể để KTTN phát triển trong thời gian tới. Nghị quyết đánh dấu mốc quan trọng trong tư tưởng, đường lối phát triển KTTN, đồng thời góp phần rút ngắn khoảng cách giữa lời nói và hành động, tạo niềm tin cho doanh nhân, doanh nghiệp; tạo nền tảng để xóa bỏ mọi định kiến, rào cản để KTTN vươn cao và vươn xa.

Tài liệu tham khảo

1. Ban kinh tế Trung ương, Báo cáo tổng kết 15 năm (2002 - 2017) thực hiện Nghị quyết Trung ương 5 khóa IX về tiếp tục đổi mới cơ chế, chính sách, khuyên khích và tạo điều kiện phát triển kinh tế tư nhân.

2. Bài phát biểu khai mạc và bế mạc Hội nghị Trung ương 5 khóa XII của Tổng Bí thư Nguyễn Phú Trọng.

3. Nguyễn Hồng Sơn, Phạm Thị Hồng Điệp (Trường Đại học Kinh tế - Đại học Quốc gia Hà Nội), Phát triển kinh tế tư nhân ở Việt Nam: Quan điểm của Đảng và một số vấn đề đặt ra, Tạp chí Cộng sản (2017).

4. Tổng cục Thống kê, Sách Hiệu quả của các doanh nghiệp trong nước giai đoạn 2005 - 2014.

5. Phạm Minh Chính - Vương Quân Hoàng (2009), Kinh tế Việt Nam: Thăng trầm và đột phá.

1 Kinh tế tư nhân được dùng để chỉ các thành phần kinh tế dựa trên chế độ sở hữu tư nhân về tư liệu sản xuất, bao gồm kinh tế cá thể, tiểu chủ và kinh tế tư bản tư nhân.

2 Nghị quyết số 10-NQ/TW 03/6/2017 về phát triển KTTN trở thành một động lực quan trọng của nền KTTN định hướng XHCN. 


\section{Tài liệu tham khảo:}

[1] Ban kinh tế Trung ương. (2017). Báo cáo tổng kết 15 năm (2002 - 2017) thực hiện Nghị quyết Trung ương 5 khóa IX về tiếp tục đổi mới cơ chế, chính sách, khuyến khích và tạo điều kiện phát triển kinh tế tư nhân.

[2] TBT Nguyễn Phú Trọng. (2017). Phát biểu của Tổng Bí thư Nguyễn Phú Trọng bế mạc Hội nghị lần thứ năm Ban Chấp hành Trung ương Đảng (khóa XII). https://tulieuvankien.dangcongsan.vn/van-kien-tu-lieu-ve-dang/hoinghi-bch-trung-uong/khoa-xii/phat-bieu-cua-tong-bi-thu-nguyen-phutrong-be-mac-hoi-nghi-lan-thu-nam-ban-chap-hanh-trung-uong-dangkhoa-xii-565

[3] Nguyễn Hồng Sơn, Phạm Thị Hồng Điệp. (2017). Phát triển kinh tế tư nhân ở Việt Nam: Quan điểm của Đảng và một số vấn đề đặt ra. Tạp chí Cộng sản (09-06). https://www.tapchicongsan.org.vn/web/guest/nghien-cu//2018/45322/phat-trien-kinh-te-tu-nhan-o-viet-nam--quan-diem-cuadang-va-mot-so-van-de-dat-ra.aspx

[4] Tổng cục Thống kê. (2016). Hiệu quả của các doanh nghiệp trong nước giai đoạn 2005 - 2014. NXB Thống kê, Hà Nội.

[5] Phạm Minh Chính, Vương Quân Hoàng. (2009). Kinh tế Việt Nam: Thăng trầm và đột phá. NXB Chính trị quốc gia, Hà Nội. 